\title{
RÍTMICA DALCROZE E O CANCIONEIRO INFANTIL: REFLEXÕES E POSSIBILIDADES DE SENSIBILIZAÇÃO CORPORAL E MUSICAL
}

\author{
Hozanan Santos Leal \\ Universidade Federal dos Vales do Jequitinhonha e Mucuri, Diamantina, Minas Gerais, Brasil \\ José Rafael Madureira \\ Universidade Federal dos Vales do Jequitinhonha e Mucuri, Diamantina, Minas Gerais, Brasil
}

\begin{abstract}
Resumo
O artigo apresenta uma pesquisa bibliográfica sobre os conceitos da Rítmica Dalcroze na Educação Física escolar como contribuinte no processo de formação e desenvolvimento da criança. Com isso, foi desenvolvida uma proposta pedagógica para a educação infantil que consiste no cancioneiro infantil associado ao trabalho da Plástica Animada como uma estratégia de musicalização, sensibilização rítmica e desenvolvimento da expressividade do corpo. Foram selecionadas três músicas do cancioneiro infantil e, a partir delas, são apresentadas formas de trabalho para a Educação Infantil.
\end{abstract}

Palavras-chave: Rítmica. Arte. Educação Física e Ensino.

\section{Introdução}

A Rítmica originou-se entre o final do século XIX e o início do século XX através de Émile Jaques-Dalcroze (1865-1950), que era um grande professor de música, também maestro, diretor teatral, pianista, cantor, ator, compositor e escritor. Nesse período, a Educação Física ainda não era consolidada, ou seja, (ainda) como ginástica, era um campo (ainda) aberto, em formação, sendo que os médicos, fisiologistas e psicólogos estavam à frente desse processo. Não havia formação em Educação Física, no entanto, Dalcroze teve muita intuição ao criar a Rítmica, pois ele não tinha formação nessa área, mas cotejou alguns métodos que já estavam estruturados, como o método alemão, o sueco, entre outros (DEL PICCHIA; DAROCHA; PEREIRA, 2013).

Trabalhando como professor de solfejo superior e harmonia no Conservatório de Genebra, Dalcroze começou a analisar os seus alunos, percebendo que eles apresentavam dificuldades em relação ao ritmo.

Dalcroze afirmava que o ritmo é a base do movimento. Com isso, o ritmo tornou-se fundamental para a aprendizagem de qualquer arte ou manifestação em que haja movimento, pois ele é algo natural ao ser humano, está em nós de forma instintiva. O grande problema, todavia, é que os alunos de música não estudavam o ritmo de uma forma adequada, ou seja, não de uma forma orgânica, mas somente como abstração aritmética.

Dalcroze percebeu que não basta apenas ouvir com o ouvido para que se possa desenvolver a conscientização rítmico-musical, mas sim com a inteireza do corpo. 
Havia um erro no ensino de música da época, que limitava de certa forma os alunos. Dalcroze descreveu que eles eram incapazes de ouvir aquilo que escreviam na partitura, eram desprovidos do "ouvido interior". Dalcroze era um músico virtuose. Ele tinha essa capacidade já desenvolvida. E quem não tinha? Como desenvolvê-la? Por que os alunos eram totalmente dependentes do piano para conhecer o resultado sonoro e musical de seus estudos de composição? Nesse sentido, Dalcroze não recomendava o uso do piano para os alunos de composição, do contrário, eles seriam dependentes do instrumento até o resto de suas vidas, não havendo o desenvolvimento da "audição interior". Com as novas tecnologias e softwares de edição e composição, a situação deve ter piorado, ou será que as ideias de Dalcroze estão presentes nas graduações em composição e regência que duram seis anos?

Assim, ele sentiu a necessidade de criar novas formas pedagógicas para que os seus alunos pudessem ter esse aprendizado.

\begin{abstract}
Apliquei-me, portanto, a inventar exercícios destinados a reconhecer a altura dos sons, a medir os intervalos, a escrutar os sons harmônicos, a individualizar as diversas notas dos acordes, a seguir os desenhos contrapontísticos das polifonias, a diferenciar as tonalidades, a analisar as relações entre as sensações auditivas e as sensações vocais, a desenvolver as qualidades receptivas do ouvido e graças a uma ginástica de um novo gênero destinada ao sistema nervoso a criar, entre o cérebro, o ouvido e a laringe, correntes necessárias para fazer do organismo, como um todo, algo que pudesse ser denominado ouvido interior (DALCROZE, 2010, p.220).
\end{abstract}

Com isso, ele criou um método ginástico, inicialmente denominado Ginástica Rítmica, uma forma de treinamento corporal que integra o corpo todo, trabalhando a audição de forma total e sendo utilizada como instrumento de preparação para todas as artes, principalmente para a música, para o teatro e para a dança.

Essa proposta de Dalcroze faz-se bastante pertinente. Pois a realidade não mudou muito nos tempos atuais. A prática pedagógico-musical continua ainda bem limitada, restritiva.

O método de Dalcroze parte de uma visão que vai além da superficialidade nos estudos musicais. Ele impõe uma discussão, que certamente incomoda uma grande parte dos músicos.

Na verdade, percebem-se em grande parte de músicos que têm muita técnica na execução de peças complexas algumas limitações de ordem auditiva, pois estão presos e endurecidos, preocupando-se apenas com a execução técnica e com a interpretação da notação musical (partitura).

Dalcroze traz algo que é bastante interessante, que é a proposta de ter um trabalho maior do "ouvir", do "sentir" com os alunos de música, apoiando seus estudos da técnica.

Dessa forma, fazer o trabalho de movimento utilizando todo o corpo humano será extremamente impactante para o ser que reage em cima do mesmo. E, consequentemente, será maior ainda o desenvolvimento do ouvido interno, pois, além de exercitar a audição musical, o aluno compreenderá as notas, suas alturas e intensidades pela sensação física que vai internamente do corpo à mente.

\title{
As origens da Rítmica de Jaques-Dalcroze na Educação Física
}

A Rítmica torna-se importante no contexto geral da área de Educação Física, pois contribui com a formação do profissional, ao mostrar-lhe as diferentes percepções e formas de aplicações do ritmo nos movimentos em geral.

Os métodos ginásticos vindos da Europa, com a Escola Francesa, Escola Sueca e Escola Alemã, eram embasados nas ciências mais destacadas da sociedade na época - a Biologia, a Anatomia e a Fisiologia -, tendo como objetivo o "corpo saudável", forte, correto e 
hábil, principalmente para as mulheres serem mais preparadas para gerar um filho, que seria um cidadão da pátria.

Mesmo com a forte característica militar, esses métodos europeus começaram a propor exercícios com base na Rítmica a partir do século XIX. Como a Ginástica Coletiva proposta pela Escola Alemã, com exercícios de marcha e ordem unida criados por Adolph Spiess (1810-1858); a Ginástica Estética e a Ginástica Pedagógica, propostas pela Escola Sueca, com exercícios harmoniosos completados com a dança, criadas por Pehr Henrick Ling (17761839), e a Ginástica Civil, criada por D. Francisco de Amoros (1770-1848), com exercícios elementares ritmados com canto (SOARES, 2001).

No Brasil, a Educação Física originou-se através da sistematização dos métodos ginásticos vindo da França, Suécia e Alemanha, juntamente com a Ginástica Civil, a Ginástica Militar, a Ginástica Médica e a Ginástica Cênica (AMOROS apud MARINHO, 1971, p.53).

Marinho (1971) vai conceituar a Educação Física como algo que extrapola a ginástica corretiva, englobando atividades que vão desenvolver o intelecto, a coordenação motora, a imaginação, a criatividade, a criticidade e a socialização do sujeito, principalmente da criança.

A Educação Física para a criança é de extrema importância, e Marinho criticava o fato de que as atividades voltadas para as crianças, na maioria das vezes, não eram as mais adequadas.

$\mathrm{Na}$ maioria das vezes, utilizavam atividades caracterizadas como trabalho forçado, conceituado pelo neurologista e psicólogo Édouard Claparède, grande especialista em desenvolvimento infantil que foi parceiro de Dalcroze na criação e na elaboração das bases da Rítmica.

Assim, Marinho conceituou formas de atividades para serem utilizadas na Educação Física, através de conceitos de Claparède, nos antigos ensinos pré-primário e primário, que constituíam a educação infantil. Suas atividades consistiam na arte e no jogo. De fato, a arte é uma forma de jogo, na qual se tem a possibilidade de brincar. $\mathrm{O}$ jogo e a arte podem andar juntos, quando tratamos de jogos de imitação, dramatização, a música, o teatro e a dança. Segundo Jesualdo (apud Marinho 1971), toda criança tem aptidão para as atividades artísticas. Já Dalcroze dizia que toda criança nasce artista. Com isso, o jogo pode ser trabalhado juntamente com a arte no processo educativo da criança nas aulas de Educação Física.

O jogo é considerado a atividade mais significativa no ensino infantil, pois é uma das atividades mais antigas da existência humana. Passa a ser estudado de forma mais profunda no século XIX para diferentes objetivos, tendo uma grande relevância dentro da educação. Para Claparède (apud Marinho 1971), o jogo funciona como agente de transmissão de ideias e de costumes de uma geração à outra, mostrando-se como grande ferramenta educativa. O seu caráter lúdico torna-o motivante, prazeroso, proporcionando um interesse maior por parte do aluno.

Um dos seus jogos ligado à conscientização rítmica são as bandinhas rítmicas, jogos com objetos, com músicas, para criar, imaginar e produzir sons, sendo realizados também com instrumentos musicais, principalmente de percussão, com os quais a criança poderá iniciar-se musicalmente e amadurecer-se ritmicamente.

Também são as sessões dramatizadas e os brinquedos cantados, nos quais as crianças interpretam personagens que elas mesmas escolhem. Com isso, elas têm muito mais liberdade e criatividade para representar, por meio de gestos, movimentos, atitudes e comportamentos.

Com essas formas de atividade, Marinho parte de uma concepção de Educação Física sucessora à concepção chamada tradicional. Trata-se de uma concepção mais científica, reunindo os elementos e conteúdos das ciências mães, dentro de uma percepção mais humanística e artística, não ficando presa apenas ao aprendizado da execução técnica para uma correção do corpo, como é na perspectiva militar. Compreende a educação do indivíduo na sua totali- 
dade, de forma lúdica e criativa. Pois nós, seres humanos, temos de ser trabalhados e educados por inteiro.

Segundo Souza Jr. (2002), a Rítmica passou a fazer parte da matriz curricular dos cursos de graduação em Educação Física no ano de 1939, quando foi criada a Escola Nacional de Educação Física e Desportos na Universidade do Brasil, no Rio de Janeiro, com a disciplina Ginástica Rítmica, por meio da Resolução no 69/69 (São Paulo-SP/CENP, 1985, p.255). Mas a grande parte das universidades brasileiras ainda não tem essa disciplina no currículo.

Há autores que fizeram estudos bem interessantes nessa área. Entretanto, o material teórico existente sobre esse tema é ainda pequeno em relação aos outros campos constituintes da Educação Física. Acreditamos ser reflexo disso a má formação de professores da área dentro da educação básica brasileira.

Na década de 1950, Marinho colocava a partitura nos seus trabalhos para os professores de Educação Física. Hoje, uma partitura, para um professor de Educação Física, é o mesmo que uma folha com escritos em grego ou aramaico.

Através de estudos de Souza Jr. (2002) e Piccolo (1992), diversos autores comprovam e afirmam que o ritmo é o processo natural e fundamental para que haja movimento. Logicamente, ele é responsável para a produção de movimento. Como um profissional do movimento, que é o da Educação Física, pode não ter domínio desse fenômeno? Com essa pergunta, certamente há algo que tem de ser revisto no processo de formação dos professores de Educação Física, a fim de para refletirmos sobre o papel desse professor em suas aulas, na educação básica e até no ensino superior. Pois qual professor queremos para nossos alunos? O reprodutor de gestos inconscientes? Ou o verdadeiro educador do sujeito na sua totalidade?

É claro que, nos últimos anos, houve uma maior ampliação de estudos relacionados ao conteúdo da educação rítmica. Mesmo com o trabalho de Dalcroze no século XIX, até hoje o estudo sobre o ritmo musical dentro da Educação Física ainda é considerado algo novo.

Há materiais consistentes tratando da percepção rítmica nos estudos de música, mas ainda há poucos estudos do trabalho rítmico com a utilização do corpo, na forma de conscientização rítmica. Em relação à totalidade do indivíduo, a presença do movimento corporal como um todo, acreditamos que ainda estão em aberto as possibilidades de trabalho rítmico que poderá levar ao desenvolvimento mais efetivo do ser humano.

Algo para que chamamos atenção é o caminho para a "mecanização" da Educação Física. Piccolo menciona que "o professor de educação física se preocupa com o movimento como um produto acabado, aplicando estratégias inadequadas visando eficiência nos resultados, sendo algo destrutivo para a criança" (PICCOLO, 1992, p.306).

Devemos questionar a reprodução dos movimentos sem qualquer consciência, vinda do tecnicismo. Isso é algo para que é necessário chamar a atenção, porque a Educação Física ainda prende-se ao rumo da aptidão física, ou seja, à busca do condicionamento físico. E isso reduz a Educação Física a apenas um "adestramento corporal", des viando o olhar para todas as outras riquezas que a nossa área compõe.

Há um equívoco por parte dos profissionais da Educação Física, que acham que técnica é só a imitação do gesto, sem conceituá-la de forma integral, tendo uma ideia fragmentada de ser humano. Como afirma Lima e Rüger (2007), instaurou-se uma franca dicotomia entre as coisas do espírito e da matéria, fato que propiciou a criação de um ser humano cada vez mais fragmentado diante da natureza e do universo. Na verdade, não há fragmentação, a técnica é parte integrante do processo. Sem técnica, não há arte, é o aprimoramento dos gestos com a consciência, principalmente com sentimentos e emoções, sendo a arte sempre acompanhada do caráter lúdico.

As crianças têm necessidades, capacidades, potencialidades e limitações em relação ao seu desenvolvimento. Mas nada disso poderá ser explorado se não houver o mínimo de inte- 
resse possível por parte da criança, pois, sem essa disposição, provavelmente ela não vai aprender (PICCOLO, 1992).

Esse trabalho pedagógico concretiza-se de uma forma positiva. Pois consegue-se perceber que o "brincar" está bastante presente, fazendo parte da naturalidade da criança, e é a verdadeira chave para o seu interesse em aprender.

Nesse aspecto, o ritmo entra com toda força, pois, quando ensinamos um movimento para a criança de forma muito mecânica, ela acaba tendo dificuldades de compreender aquele movimento. Após colocarmos uma marcação rítmica musical, a relação da criança com o movimento se torna mais próxima. Consequentemente, ela passa por outra forma de compreensão, na qual notamos uma diferença acentuada na assimilação e na aprendizagem que tem nessa ocasião.

As noções básicas necessárias para compreender o ritmo são o movimento, sua energia, o tempo e o espaço. Acreditamos que esses fatores caracterizam o ritmo; seria a forma de interiorização e exteriorização por meio da linguagem corporal e o aprendizado rítmico que levaria o desenvolvimento do ser humano em várias formas.

De fato, o desenvolvimento dos estudos relacionados a essa área requer que eles sejam aplicados na prática com as crianças, na escola, onde seus próprios corpos serão o verdadeiro laboratório de análise para atingirmos os resultados. É na prática com a criança que reconheceremos as suas necessidades que precisam ser satisfeitas e as capacidades e potencialidades que precisam ser desenvolvidas e aprimoradas. Assim, teremos condições de perceber o que de fato podemos criar para melhorar as formas de educação da criança.

\section{$O$ cancioneiro infantil associado à prática da Plástica Animada}

A educação básica brasileira, principalmente a escola pública, carece de ensino das artes. Quando tratamos do aprendizado rítmico-musical, o aprendizado das artes cênicas, bem como a expressividade do corpo, é praticamente nulo nas escolas regulares. O que se pode dizer é que o sujeito não adquire essa bagagem de conhecimento na sua vida escolar, a não ser que ele seja matriculado em uma escola de arte. E esta não é acessível a todos.

O número de crianças que têm acesso ao ensino de música, por exemplo, é muito baixo. E mesmo quando o têm, as crianças já estão um pouco mais velhas, com uma educação de forma muito rígida e restritiva, levando, por consequência, a que ocorram muitas desistências.

Mas a música, como arte, é de natureza lúdica, a sua prática é caracterizada pela experiência do prazer, da brincadeira, da alegria, da emoção, do ritmo e do movimento. Além de ajudar no processo de amadurecimento das capacidades de relações sociais, afetivas e intelectuais (MADUREIRA, 2012).

Por isso, não é a falta de conteúdo, e nem a falta de legislação, que impede a presença do ensino desses conhecimentos na educação da criança, seja em escola pública, seja na particular. De acordo com a Lei ${ }^{\circ} 11.769 / 2008$, o ensino da música está presente nos currículos das escolas brasileiras, estando em pleno vigor. Sendo assim, o ensino musical deve fazer parte do estudo sistematizado que a criança tem na escola.

Tratando-se principalmente de educação infantil, a prática pedagógica para alunos tem de ir além da sistemática existente, na qual, na grande parte das escolas, o aluno fica sentado em uma carteira durante quase todo o tempo. Desde muito cedo, o aluno já tem de submeterse a um certo molde, com uma rigidez muito grande, que se torna indevida nessa fase.

Deste modo, pode-se perguntar, onde está o corpo dessa criança? Onde está a sua expressividade? A sua relação prática com a imaginação e a criação? Seu desenvolvimento íntegro como corpo? Esse sistema, de certa forma, tende a anular uma rica gama de potencialidades que a criança tem para desenvolver, além de ser algo desestimulante e bastante cansativo 
para a criança, que fica a maior parte do tempo sentada em uma carteira sem poder fazer muita coisa.

Geralmente, na educação infantil, o professor regente da turma é responsável por todos os conteúdos a serem lecionados. E isso é praticamente impossível, um profissional com uma única formação dar conta da ampla gama de conteúdos para formar uma criança, ou seja, a base para formar um sujeito.

Desta forma, ressaltamos a presença da Educação Física, representada pelo seu professor como contribuinte para essa formação, assim como os professores das Artes, como a música, a dança, as artes plásticas e o teatro.

Há pesquisas e dados tratando da música na educação infantil no nosso país, que apresentam reflexões favoráveis à presença da música na escola. De acordo com as informações de Brasil (1998), a vivência musical para a criança pode propiciar a integração de experiências que passam pela percepção e pela prática, como ouvir música, participar de jogos através de músicas ou de brincadeiras de roda.

Por meio do desenvolvimento através do aprendizado desses conteúdos, as crianças passam a atingir patamares que são mais sofisticados, pois começam a ter domínio de tais conhecimentos. Essa experiência propicia uma transformação ou até uma recriação desses conhecimentos.

\footnotetext{
O gesto e o movimento corporal estão ligados e conectados ao trabalho musical. Implica tanto em gesto como em movimento, porque o som é, também, gesto e movimento vibratório, e o corpo traduz em movimento os diferentes sons que percebe (BRASIL, 1998, p. 61).
}

Os anos iniciais na vida do indivíduo são de extrema importância, pois nessa fase é que são despertadas todas as suas potencialidades, sejam elas em qualquer âmbito, principalmente intelectual e criativo. Se, no momento da infância, não houver o trabalho com a experiência, será uma perda para um desenvolvimento diferenciado, em qualquer habilidade.

A arte é criação. Trabalhada na escola, poderá fazer aflorar o artista que há em cada um de nós - e isso, de fato, ocorre com maior possibilidade na infância.

Com isso, propomos neste trabalho um processo de desenvolvimento rítmico-musical e da expressividade do corpo para alunos da educação infantil, no qual é usado o método Dalcroze, mais especificamente a Plástica Animada, associada às canções infantis. A Educação Física pode ter uma grande contribuição nesse aspecto, utilizando o corpo como instrumento de sensibilização rítmica no processo de musicalização e proporcionando o desenvolvimento da totalidade do corpo, como também a sua expressividade.

A Plástica Animada é a tradução da linguagem musical através de gestos e expressões do corpo, trazendo a música para uma linguagem visual corporal. Desse modo, o corpo tornase um veículo de captação dos movimentos da música, as suas pausas, intensidades, o compasso, os acordes, fraseados e progressões harmônicas. Para cada movimento que a música apresenta, há uma correspondência gestual, como se fosse o movimento vivo da música, que pode inspirar e cultivar o processo criativo do corpo como um todo (MADUREIRA, 2012).

O objetivo da Plástica Animada é compreender a música utilizando o corpo que é um instrumento vivo e que pode sentir a música como um todo, como uma espécie de audição com a inteireza do corpo. Com isso, qualquer elemento musical pode ser demonstrado através do movimento corporal, seja de forma literal, seja fazendo uma construção figurativa. Incide na coordenação motora e no enriquecimento das potencialidades do corpo na sua totalidade, através da compreensão dos impulsionadores da música por meio do movimento proposital.

É uma das três partes principais que compõe a Rítmica, juntamente com o Solfejo e a Improvisação. Inicialmente, é feita por movimentos e gestos corporais e, depois, por melodias vocais e instrumentais, seja em grupo, seja também individualmente (MADUREIRA, 2012). 
Para uma criança que fica a maior parte do tempo sentada em uma carteira, ao oferecer uma rica variação de experiências e formas de aprendizagem com todo o corpo, propicia uma diferença significativa na sua formação.

Não há como aprender ritmo sem movimento do corpo. Para os autores da área, como o próprio Dalcroze, não existe ritmo sem movimento. O ser humano é corpo, e o corpo vive através do movimento.

É ainda mais importante e necessário esse trabalho educacional com o ritmo, juntamente com o movimento corporal, com crianças do ensino infantil. Pois é nessa fase que a criança vai receber os primeiros estímulos, que fazem toda a diferença no desenvolvimento futuro daquele ser humano. Portanto, esse processo já não terá a mesma efetividade na adolescência ou na juventude. Mas ainda podemos colher alguns frutos com os universitários e até com a terceira idade.

Também deve-se dar a devida importância para que a criança possa fazer a descoberta do corpo, como se fosse uma espécie de laboratório dentro de si, tendo as possibilidades de movimento e desenvolvimento, juntamente com o ritmo e outras qualidades físicas e expressivas.

O que se faz interessante nesta proposta é utilizar a riqueza que há no cancioneiro infantil, com as diferentes canções existentes, cada uma com as suas peculiaridades e suas variações de elementos rítmico-musicais, que devem ser explorados da melhor forma possível pela criança, aproveitando a familiarização que ela tem com essas canções.

Quando oferecemos um ambiente de vários sons, até mesmo a música para criança em diferentes situações, fazemos com que a criança, intuitivamente, inicie seu processo de musicalização, escutando diferentes sons de objetos, brinquedos, do ambiente e do próprio corpo, apresentando observações, reações e descobertas. Fazendo com que o gesto e o movimento corporal fiquem conectados à música, como uma espécie de movimento vibratório, ela tem a capacidade de traduzir os diferentes sons e sequências rítmicas que percebe através do movimento proposital.

Isso se torna uma forma de jogo bastante rica para o desenvolvimento da criança, por meio da brincadeira, como "brincar" explorando as sonoridades, em que possa experimentar as possibilidades da sua voz, do canto, primeiramente tentando imitar o que ouve. Assim, o aluno começa a entrar no processo de assimilação e passa a conferir significado, agrupando e entendendo o que ouve.

Desse modo, o aspecto da imaginação e da criação da criança começa a ser aflorado, ou seja, a sua musicalidade, estimulando o desenvolvimento da sensibilidade, criatividade e senso rítmico. A partir do prazer de ouvir a música, desenvolve a imaginação e novas formas de organização das experiências. Nisso, a criança constrói determinados saberes que serão essenciais para o resto da vida.

Há certa exigência motora para a criança desenvolver a sua precisão nos elementos rítmicos e sonoros da música. Então, o processo precisa e deve ser trabalhado de forma progressiva. Para tanto, primeiramente a criança deve conhecer o seu corpo, a fim de que possa desenvolver um domínio sobre ele.

As formas de movimento da criança, os seus gestos, devem ser controladas, cadenciadas no seu devido tempo e espaço, sem perder a harmonia existente entre os dois, nem a naturalidade. Assim, terá um sentimento único sobre aquela determinada música que está sendo escutada (PICOLLO,1992).

Outros aspectos que podem também interferir são a forma como a música é executada e a quantidade e a qualidade dos instrumentos que são utilizados. Tudo isso faz diferença no processo, porque desperta o artista que há dentro de cada pessoa com potencialidades fantásticas. Sem esse processo de aprendizagem presente na vida da criança, esse fenômeno não irá despertar sozinho. 


\section{Formas de trabalho com as músicas infantis}

O cancioneiro infantil constitui-se de um vasto repertório musical, composto por diversas músicas com melodias, ritmos, harmonias e letras diferentes. Cada uma apresenta peculiaridades próprias, permitindo a criação de diferentes formas de trabalho com a Plástica Animada, as quais vão depender do perfil do professor, da sua criatividade, da identidade dos alunos, bem como das suas potencialidades de imaginação, de criação, da sua relação com o jogo e também suas limitações.

O mais interessante é que as músicas infantis sempre são muito bem aceitas pelas crianças. Em qualquer lugar, toda criança tem vontade de brincar com essas canções, de forma mais natural possível.

Assim, escolhemos e transcrevemos três músicas do cancioneiro infantil para esta proposta: "Ciranda cirandinha", "Pezinho" e "Sambalelê".

\section{Ciranda, cirandinha}
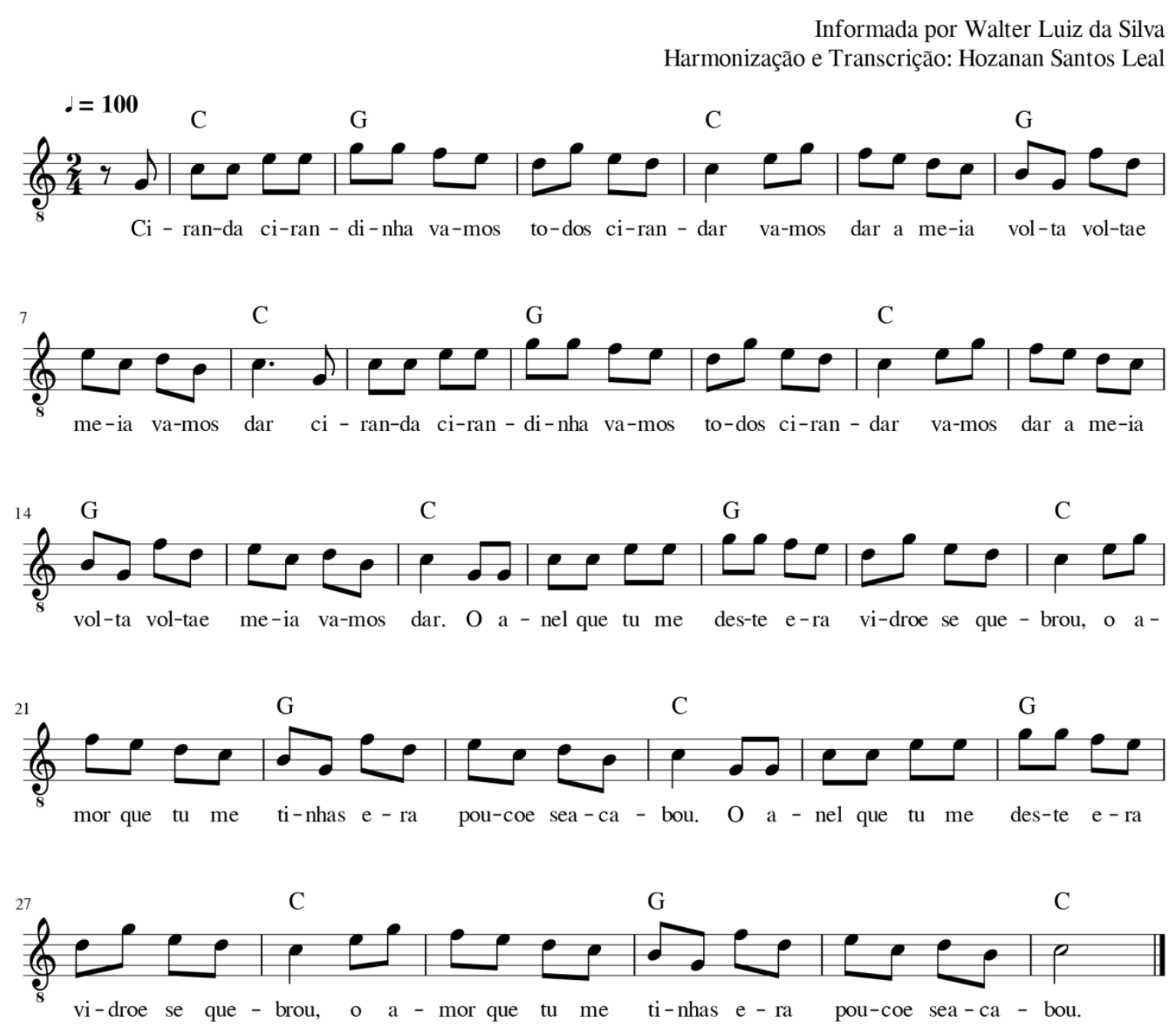
Observação: Tivemos acesso a essas músicas através do professor Walter Luiz da Silva (docente do Departamento de Educação Física/UFVJM), diamantinense, e muito conhecedor das tradições da mesma. Ele nos mostrou um livrinho de capa verde, muito antigo, o qual mantém muito bem guardado, acreditamos que poucos tiveram acesso a essa obra. Nela, há músicas tradicionais do cancioneiro infantil, ainda muito presentes na cultura popular regional.

Desenvolvimento: Inicialmente, as crianças ficarão espalhadas por todo o espaço (sendo um salão ou um pátio, que não tenha nenhuma interferência sonora no local). Elas terão de caminhar de acordo com o compasso da música. O professor poderá ajudar na percepção, colocando mais ênfase no apoio e no impulso, com o auxílio do instrumento musical (o qual pode ser também de percussão).

\section{Exemplo:}

-"Ciranda, cirandinha"

(Inclinar o corpo para frente com os braços no alto)

- "vamos todos cirandar"

(Flexão de quadril para baixo com os braços moles balanceando)

- "vamos dar a meia volta"

(Agachar e dar um giro)

- "volta e meia vamos dar"

(Dar dois passos para trás e bater palmas uma vez) 


\section{Pezinho}

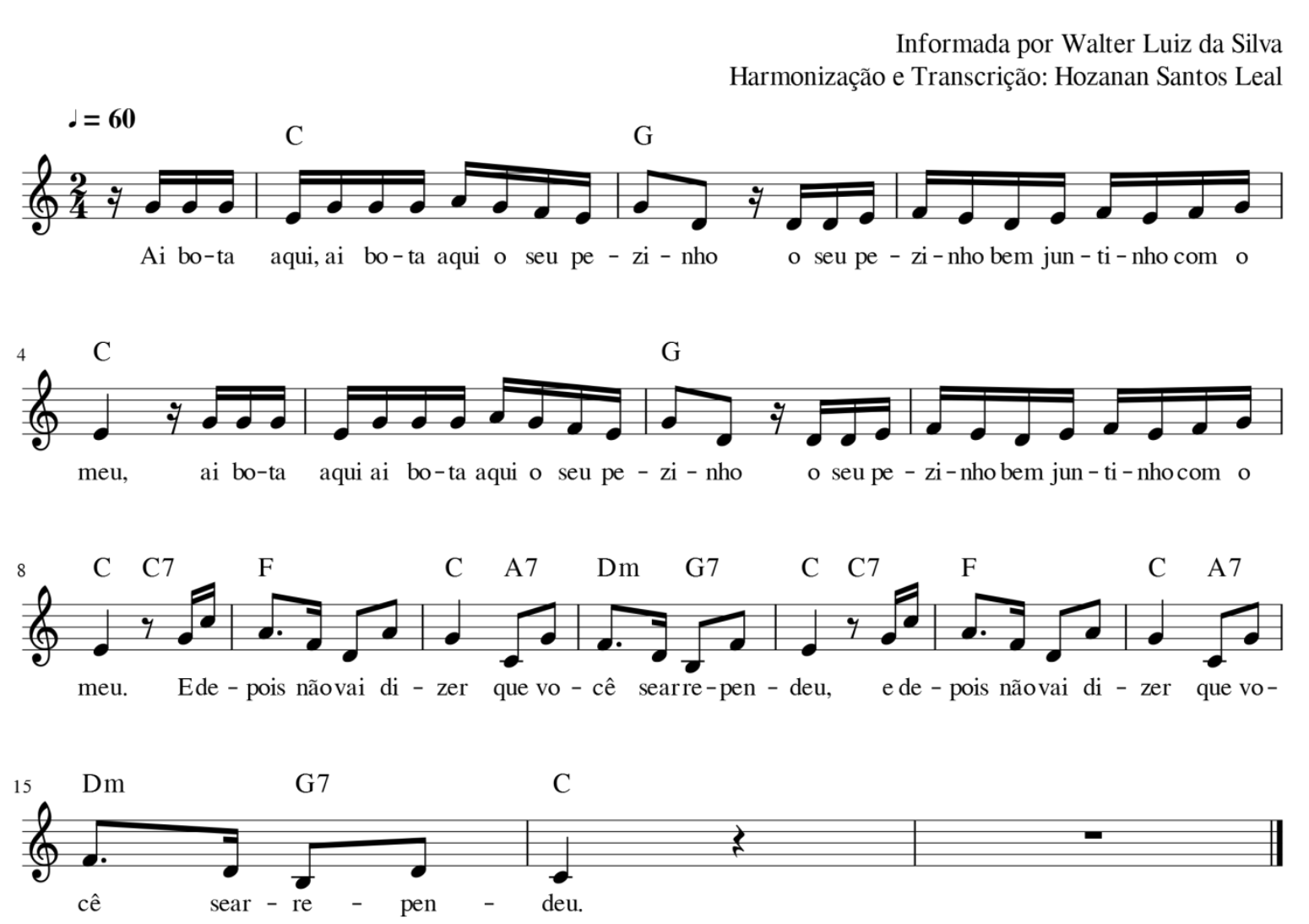

Desenvolvimento: Inicialmente, os alunos ficarão se deslocando pelo espaço, caminhando naturalmente, ouvindo e sentindo o ritmo, a pulsação da música, um processo de internalização do ouvido rítmico-musical, de forma fluente com todo o corpo. Em seguida, cada elemento da melodia terá um gesto corporal correspondente. Esses gestos serão ensinados pelos professores ou podem ser criados junto com os alunos.

\section{Exemplo:}

- "Ai bota aqui, ai bota aqui o seu pezinho"

(Dois passos lentos suaves, passar uma mão nos pés e depois subir)

- "o seu pezinho bem juntinho com o meu"

(Passar as mãos nos pés, saltitando para trás, e pôr as duas mãos ao peito)

Depois de os alunos terem a experiência dos movimentos, somente o professor vai fazê-los.

Os alunos cantam de acordo com os movimentos do professor, sendo um solfejo corporal. 


\section{Sambalelê}

Informada por Walter Luiz da Silva Harmonização e Transcrição: Hozanan Santos Leal
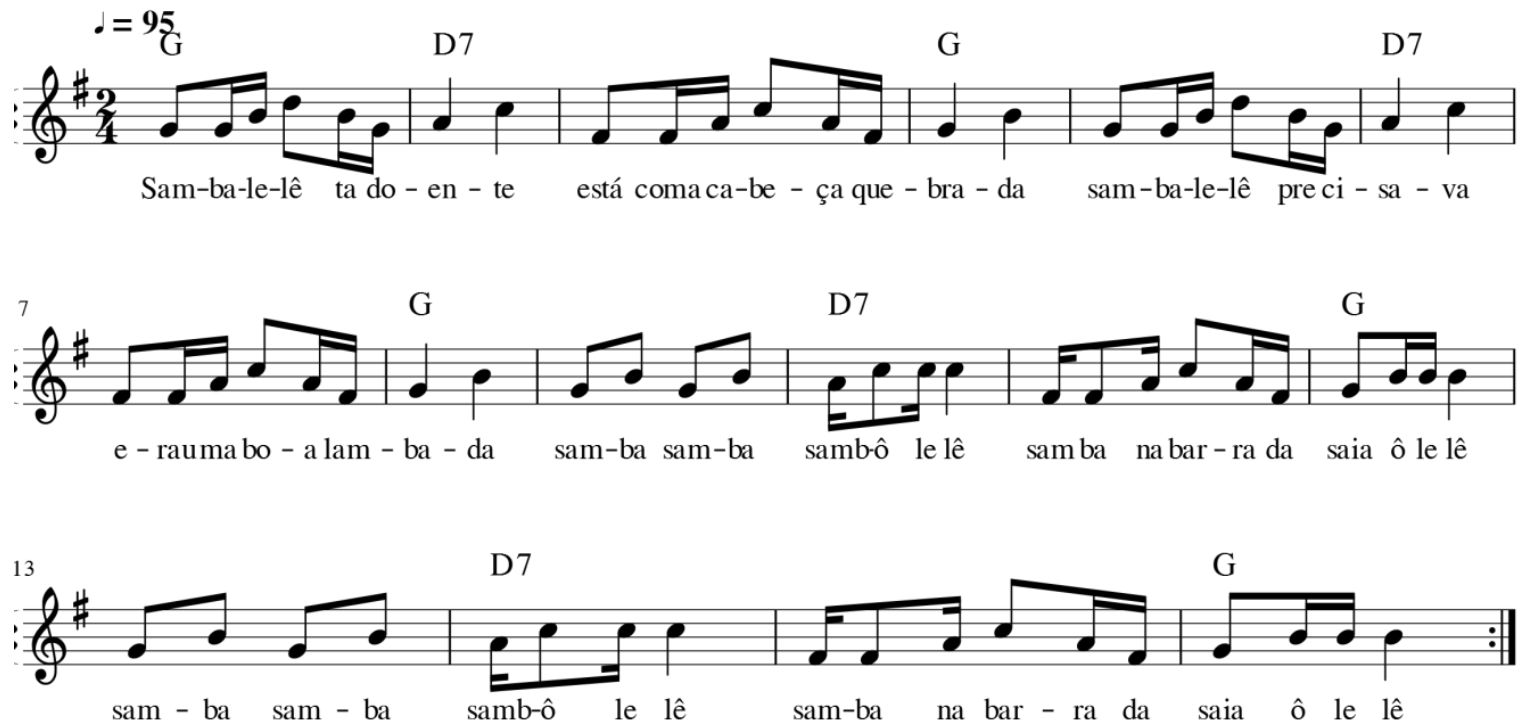

Desenvolvimento: As crianças ficam espalhadas em todo o espaço. Será proposto um trabalho rítmico em que cada aluno vai bater os pés no chão e, no final, batem palmas com as mãos uma vez, de acordo com o ritmo da música. O professor pode propor variações nos ritmos a serem seguidos com os pés e as mãos, dependendo do progresso que a turma apresentar no processo de conscientização rítmica. Pode dar destaque nas maiores intensidades da música, quando poderá também fazer gestos com maior energia nas notas mais altas.

Exemplo:

- "Sambalelê está doente"

(Saltitar com os pés e no final levantar os braços e bater palma)

- "está com a cabeça quebrada"

(Saltitar com os pés e no final bater as mãos nas coxas)

Em seguida, pode-se fazer o mesmo trabalho que foi apresentado na música anterior. Depois de os alunos internalizarem as figuras rítmicas e melódicas da música, o professor passa a fazer os movimentos, e os alunos cantam de acordo com os movimentos apresentados.

\section{Conclusão}

O ensino da Rítmica na Educação Física brasileira ainda é pouco difundido, principalmente nas escolas do ensino regular. Este trabalho vem contribuir para possibilitar o incremento do ensino desse conteúdo nas escolas de educação infantil, reforçando um processo de ensino-aprendizagem mais ampliado, para uma formação mais totalizada do sujeito.

De fato, a Educação Física, com o trabalho do corpo no processo de sensibilização musical e rítmica, se apresenta como uma grande área contribuinte no dever de educar e formar a criança que se encontra no espaço escolar. Esse trabalho com a música e o movimento não é algo novo, sempre fez parte dessa área, começando por Dalcroze até chegar nos dias de hoje. Evidentemente é um campo que ainda está aberto a novos estudos, pois há uma ca- 
rência de pesquisas e trabalhos para o surgimento de novas possibilidades no contexto educacional.

A grande dúvida que ainda se tem é se realmente a sensibilização musical como o "ouvido interno" poderá chegar a todos, porque a proposta do método Dalcroze é justamente para que isso possa ser ensinado. Para Dalcroze isso era possível, mas acreditamos que ainda necessitamos de mais estudos dentro desse assunto para que possamos chegar a essa conclusão.

Dessa forma, a proposta desenvolvida se apresenta como uma forma de resgate do trabalho das canções infantis, fazendo com que esse conteúdo cultural permaneça vivo nas futuras gerações, além de possibilitar recursos fantásticos para o ensino rítmico-musical das crianças, que é um aprendizado fundamental para o desenvolvimento delas, possibilitando ao sujeito uma formação mais completa.

\title{
DALCROZE RHYTHMIC AND THE CHILDREN'S SONGBOOK: REFLECTIONS AND BODY AWARENESS AND MUSICAL POSSIBILITIES
}

\begin{abstract}
The article presents a bibliographic research on the concepts of Rhythmic Dalcroze in Physical Education as a contributor in the child's education and development. Thus, we developed an educational proposal for children's education which is the Children's Songbook associated with the work of Plastique Animée as a musicalization strategy, rhythmic awareness and the development of expressiveness of the body. Three songs from the Child's Songbook were selected, and, from them, are presented ways of working for Early Childhood Education.
\end{abstract}

Keywords: Rhythmic. Art. Physical Education and Teaching.

\section{RÍTMICA DALCROZE Y EL CANCIONERO INFANTIL: REFLEXIONES Y POSIBILIDADES DE SENSIBILIZACIÓN CORPORAL Y MUSICAL}

\section{Resumen}

El artículo presenta una investigación bibliográfica sobre los conceptos de Rítmica Dalcroze en la educación física escolar como colaborador en el proceso de formación y el desarrollo del niño. Por eso, hemos desarrollado una propuesta educativa para la educación infantil, que consiste en el cancionero infantil asociado al trabajo de Plástica Animada, como una estrategia musicalizacion, sensibilización rítmica y el desarrollo de la expresividad corporal. Se seleccionaron 3 músicas del cancionero infantil y, a partir de ellas, se presentan formas de trabajar con ellas en la Educación Infantil.

Palabras clave: Rítmica. Arte. Educación Física. Enseñanza. 


\section{Referências}

BRASIL, Ministério da Educação e do Desporto. Secretaria de Educação Fundamental, 1998. Referencial Curricular Nacional para Educação Infantil. Brasília: MEC/SEF, v. 3.

BRASIL, Secretaria de Educação Fundamental. 1997. Parâmetros Curriculares Nacionais. Brasília: MEC/SER.

COLETIVO DE AUTORES. Metodologia do ensino de Educação Física. São Paulo: Cortez, 1992.

DALCROZE, E. J. Os estudos musicais e a educação do ouvido. Pro-Posições, Campinas, v. 21, n.1 (61), p. 219-224, jan. /abr. 2010.

DEL PICCHIA, J. M. M; DAROCHA, R. A; PEREIRA, D. P. Émile Jaques-Dalcroze: fundamentos da rítmica e suas contribuições para a educação musical. Revista Modus, ano VIII, no 12, Belo Horizonte, maio 2013, p. 73-88.

LIMA, S. A; RÜGER, A. C. L. O trabalho corporal nos processos de sensibilização musical. Opus, Goiânia, v. 13, n. 1, p. 97-118, jun. 2007.

MADUREIRA, J. R. Rítmica Dalcroze e a formação de crianças musicistas: uma experiência no Conservatório Lobo de Mesquita. Revista Vozes dos Vales da UFVJM: Publicações Acadêmicas, Minas Gerais, n² 2, ano I, 2012.

MARINHO, I. P. Educação física, recreação e jogos. 2. ed. São Paulo: Cia. Brasil Editora, 1971.

PICOLLO, V. L. N. Brincando com o ritmo. Revista Brasileira de Ciências do Esporte, n.1, v.12, p.306-307, 1992.

SAVIANI, D. Escola e democracia. 34. Ed. Revista Campinas: Autores Associados, 2001. (Col. Polêmicas do Nosso Tempo; vol. 5).

SOARES, C. L. Educação física: raízes europeias e Brasil. 2. ed. Campinas: Autores Associados, 2001.

SOUZA JR., O. D. A disciplina rítmica no processo de formação dos alunos de educação física. Revista Mackenzie de Educação Física e Esporte. Ano 1, nº 1, 2002.

Recebido em: 26/05/2016

Revisado em: 11/10/2016

Aprovado em: 17/04/2017

Endereço para correspondência:

zananleal@hotmail.com

Hozanan Santos Leal

Universidade Federal dos Vales do Jequitinhonha e Mucuri

Rodovia MGT 367 - Km 583, 5000

Alto da Jacuba, Diamantina - MG, 39100-000 